Jennifer De Silva-Leonardo, MD'

Rosario R. Ricalde, MD'

Jose Roberto V. Claridad, MD 1,2,3,

Erasmo Gonzalo D.V. Llanes, MD ${ }^{1,4,5}$

'Department of Otorhinolaryngology Head and Neck Surgery

Quirino Memorial Medical Center

${ }^{2}$ Department of Otorhinolaryngology

Head and Neck Surgery

Far Eastern University -Nicanor Reyes Memorial

Foundation Medical Center

${ }^{3}$ Department of Otorhinolaryngology

Head and Neck Surgery

Capitol Medical Center

${ }^{4}$ Department of Otorhinolaryngology College of Medicine - Philippine General Hospital

University of the Philippines Manila

${ }^{5}$ Department of Otorhinolaryngology

Head and Neck Surgery

Rizal Medical Center
Correspondence: Jennifer De Silva-Leonardo, MD Department of Otorhinolaryngology Head and Neck Surgery Quirino Memorial Medical Center

Katipunan Road Ext., Project 4, Quezon City 1108 Philippines

Phone: (632) 4212250 local 117

Fax: (632) 4219289

E-mail address: jendesilvaleonardo@yahoo.com

Reprints will not be available from the author.

No funding support was received for this study. The authors signed a disclosure that they have no proprietary or financial interest with an organization that may have a direct interest in the subject matter of this manuscript, or in any product used or cited in this study.

Presented at the 10th Annual Northeast Manila ENT-HNS Training Consortium Research Contest (2nd Place), Veterans Memorial Medical Center, Quezon City, Philippines February 20, 2009;

Clinical Case Report Contest, Philippine Society of Otolaryngology- Head and Neck Surgery Mid-year Convention, Bohol Tropics Hotel, Bohol, Philippines April 24, 2009.

\title{
Extramedullary Plasmacytoma in the Maxillary Sinus
}

\begin{abstract}
Objective: To describe an intranasal mass initially diagnosed and treated as benign that eventually turned out to be a malignant extramedullary plasmacytoma of the maxillary sinus and to review the literature on its presenting signs and symptoms, diagnosis, management and pathophysiology.
\end{abstract}

\section{Methods:}

\author{
Design: Case Report \\ Setting: Tertiary Public Hospital \\ Patient: One
}

Results: A 45-year-old male with persistent nasal obstruction and intermittent epistaxis underwent several biopsies of a mass shown on computed tomography scans as heterogeneously enhancing, expansile, occupying the left maxillary sinus with extension into the left nasal cavity with areas of erosion. Immunohistochemical staining was negative for cytokeratin (CK) and leukocyte common antigen (LCA). Complete excision yielded a final histopathologic interpretation of plasmacytoma. Laboratory examinations excluded multiple myeloma. The final diagnosis was extramedullary plasmacytoma and he was treated with post-operative adjuvant radiotherapy.

Conclusion: Plasmacytoma may present in the sinu-nasal region and be part of a systemic disease like multiple myeloma. A high index of suspicion and thorough initial histopathological work-up may help in establishing a definitive diagnosis and providing optimum treatment.

Key words: Plasmacytoma, plasma cell tumor, multiple myeloma, plasma cell myeloma, extramedullary plasmacytoma

Plasmacytomas represent a localized proliferation of plasma cells. They may be primary or secondary to disseminated multiple myeloma and may arise from osseous (medullary) or nonosseous (extramedullary) sites. Primary extramedullary plasmacytomas can be solitary or multiple. ${ }^{1}$

Extramedullary plasmacytomas are localized plasma cell neoplasms that occur within soft tissues. By definition, they cannot occur within bone. They account for 1-2\% of all plasma growths and have a predilection for the upper respiratory tract without specific manifestations. 
Approximately $80 \%$ involve the paranasal sinuses, pharynx, nasal cavity, gums and oral mucosa. ${ }^{2}$ Extramedullary plasmacytomas in the head and neck are submucosal in $80 \% .^{3}$ They have a lower rate of conversion to disseminated multiple myeloma compared to solitary plasmacytoma of the bone. Progression to multiple myeloma may occur in $20-30 \%$. The 10 - year survival rate is $50-89 \% .^{2}$

\section{CASE REPORT}

A 45-year-old male with left sided nasal obstruction of four months' duration also experienced persistent rhinitis and episodes of epistaxis which resolved spontaneously. There was no history of head trauma, hypertension, mucosal or vascular injury or other systemic diseases. He self-medicated with nasal decongestants without relief. A transnasal punch biopsy performed at another institution was read as inflammatory nasal polyp and he was treated for nasal polyposis and sinusitis with unrecalled antibiotics and steroids, still without relief.

By the time he consulted at our institution for a second opinion, the mass had grown and there was a prominent bulge on the patient's left cheek. A red and smooth mass protruding from the left nasal cavity could also be seen on posterior rhinoscopy. The nasal septum was deviated and examination of the oral cavity showed a palatal bulge on the ipsilateral side (Figure 1).

A paranasal sinus CT scan with contrast showed a heterogeneouslyenhancing expansile soft tissue mass in the left maxillary sinus with extension into the left nasal cavity, opacification of the left frontal sinus and both ethmoid and left sphenoid sinuses. The posterior and anteromedial wall of the left maxillary sinus and left maxillary alveolus showed irregular areas of erosion. Calcific foci were seen at the periphery of the mass with bone fragments from the erosion or dystrophic calcification and the nasal septum was shifted to the right. Figures 2 and 3 show the axial and coronal CT scans of the patient with the pertinent findings.

A second biopsy of the sinonasal mass through a Caldwell-Luc approach revealed a thinned-out anterior wall of the left maxillary sinus containing a friable pink meaty mass with rubbery gray areas. Histopathologic examination revealed extensive necrosis and inflammation with a focus of atypical cells suspicious for malignancy.

A third biopsy through the same gingivobuccal incision yielded a histopath diagnosis of malignant round cell tumor versus acute inflammatory pattern. Immunostaining with cytokeratin and leukocyte common antigen were both negative.

A Denker's procedure revealed an absent anterior maxillary wall and eroded medial wall but smooth, intact posterior and lateral walls. There was partial erosion of the anteromedial hard palate. The left

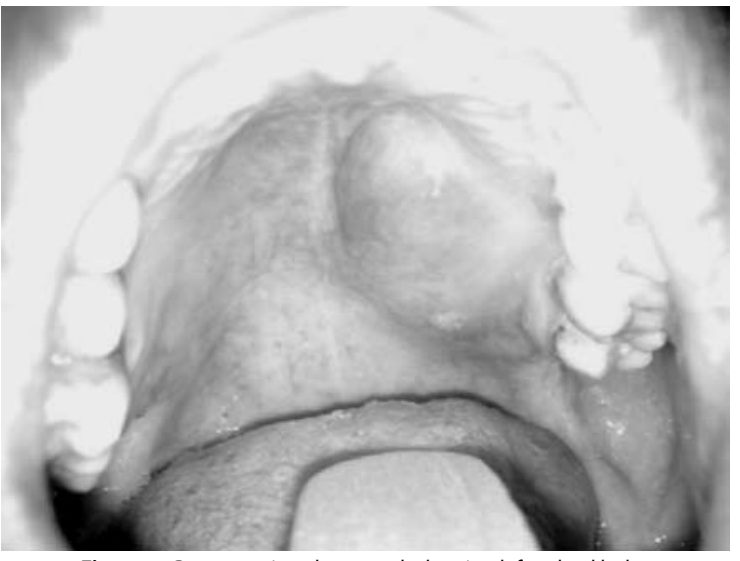

Figure 1. Pre-operative photograph showing left palatal bulge
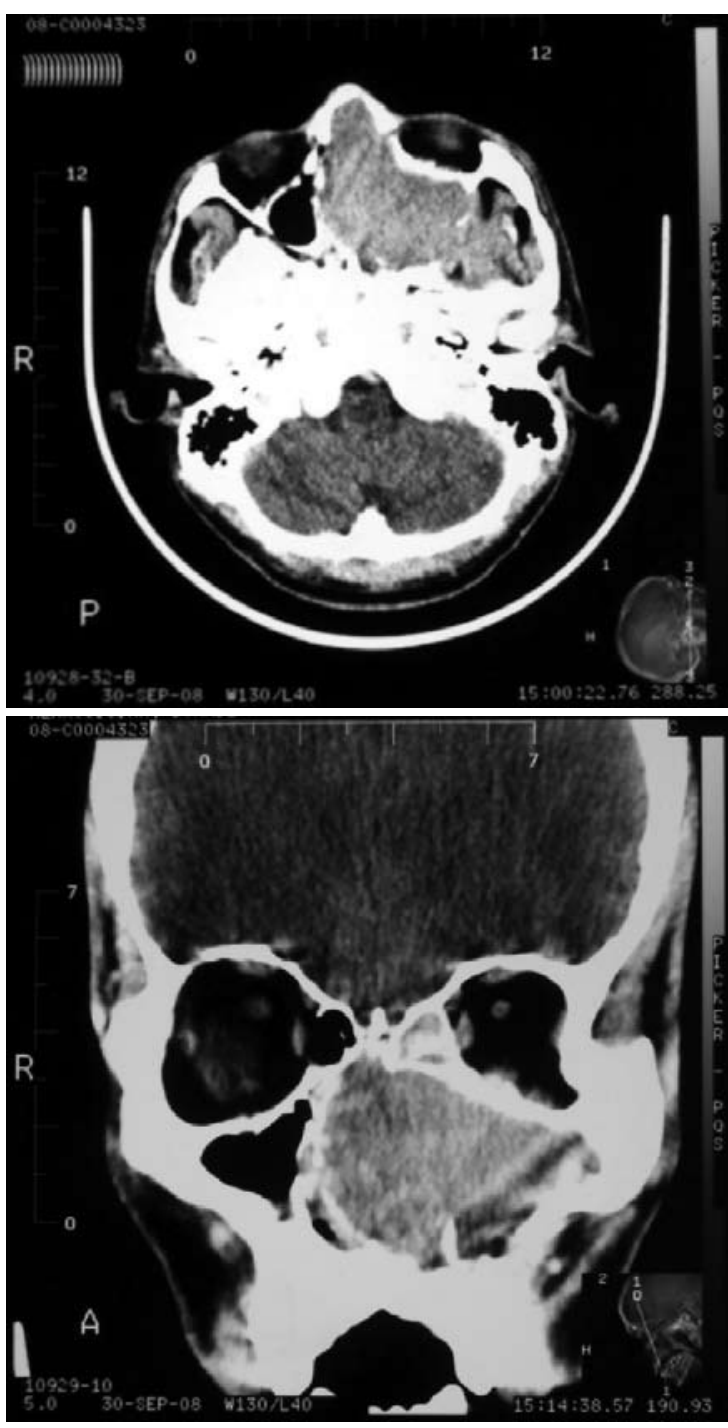

Figure 2. Axial and coronal $\mathrm{CT}$ scans with contrast showing a heterogeneously enhancing mass in the left maxillary sinus. 


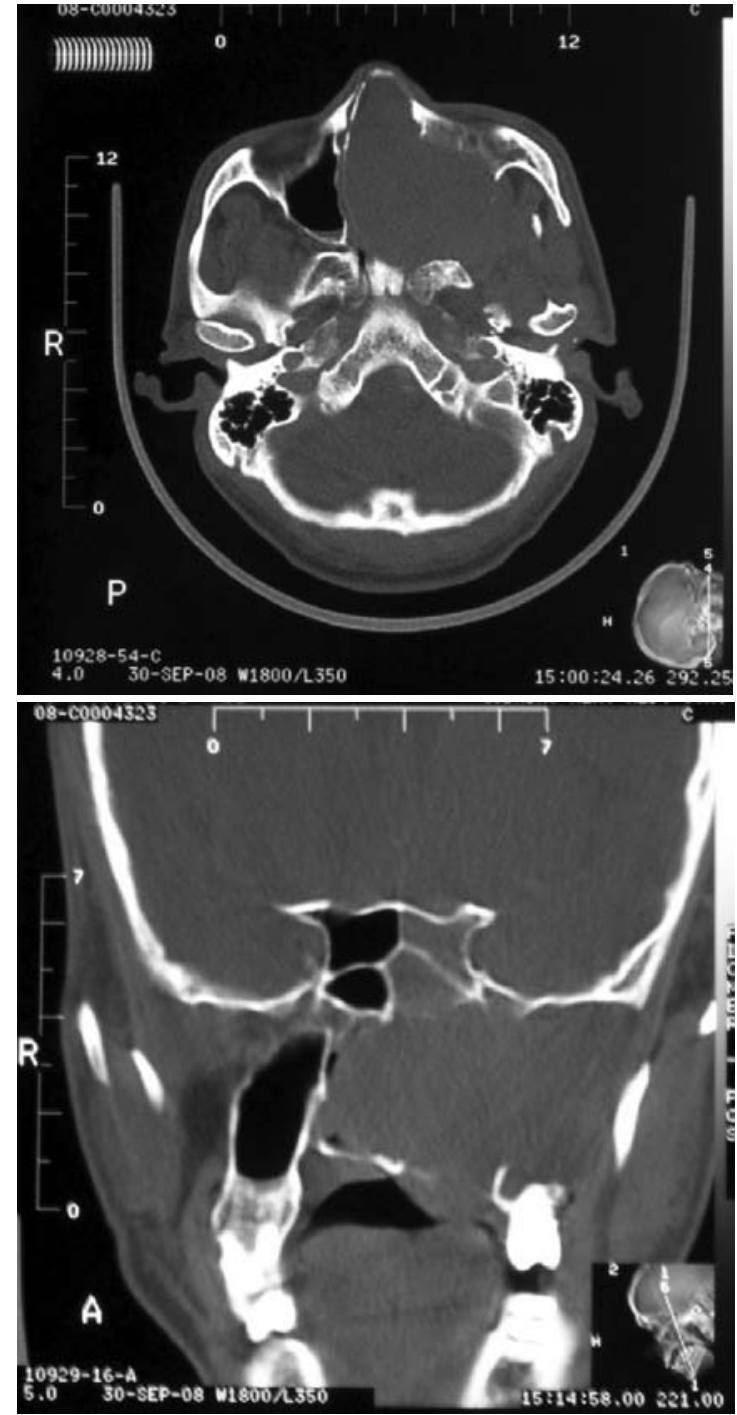

Figure 3. Axial and coronal CT scan, bone windows: expansile soft tissue mass in the left maxillary sinus extending into the left nasal cavity with irregular areas of erosion on the posterior and anteromedial wall; nasal septum markedly shifted to the right side.

inferior turbinate was absent but the middle turbinate and deviated septum were intact. The mass occupied the entire left maxillary sinus and nasal cavity and was completely excised together with remaining bony fragments.

The final histopathology reading was plasmacytoma, cytokeratinnegative, leukocyte common antigen (LCA) - negative, HMB45negative, CD 138-positive. Figure 4 shows a pictomicrograph of the specimen immunostained with CD 138.

One month post-operatively, remission of the palatal bulge was noted. Additional lab exams ruled out multiple myeloma and the patient underwent adjuvant radiotherapy and co- management with the Hematology-Oncology service. His symptoms have not recurred.

\section{DISCUSSION}

Extramedullary plasmacytomas comprise less than $1 \%$ of head and neck tumors. ${ }^{4}$ These are soft tissue plasma cell tumors found in patients with no evidence of bone marrow disease and with no findings on total body skeletal survey. However, bone erosions adjacent to the plasmacytoma may occur. Approximately $80 \%$ of head and neck extramedullary plasmacytomas arise submucosally, the most common site being the sinonasal region. ${ }^{3}$

The etiology remains unknown but some occupations exposure to certain chemicals, radiation, viruses and genetic factors have been suggested as etiologic factors. ${ }^{5}$ Our patient is an electrician who claims to have been exposed to unrecalled solvents or chemicals used to clean circuit boards and welding fumes.

The average age of patients with plasmacytoma is about 60 with men being 3-4 times more affected than women. It occurs in all races but rates are higher in African Americans and lower in the Asian population. ${ }^{6}$ The most common initial signs and symptoms are nasal obstruction and epistaxis as in this case. ${ }^{2,3,7}$ (See Table 1)

Fine needle aspiration is non-diagnostic because of the limited tissue available for special staining and for complete histologic examination. Therefore, incisional or excisional biopsy, depending on the size and location of the mass is necessary. ${ }^{3}$ Deep biopsies must be taken as the tumor is submucosal and the mucosa may be thickened as the result of an inflammatory reaction. ${ }^{8}$ This may explain the initial punch biopsy diagnosis of chronic inflammation in our case.

Radiographic assessment shows local bone destruction in most patients with nasal cavity or maxillary sinus involvement. ${ }^{9} \mathrm{CT}, \mathrm{MRI}$ and complete endoscopic examination of the aerodigestive and gastrointestinal tracts are required to determine the exact extent of the tumor and its respectability. ${ }^{8}$ CT allows improved depiction of the tumor and associated local invasion and bony destruction but remains non-specific. ${ }^{10}$

On gross examination, the masses are usually polypoid but can be sessile. They tend to appear granulomatous and red although some are yellow-gray, gray or dark brown. They are vascular and bleed easily and profusely. ${ }^{11}$

Because the lesion is not common, the diagnosis is typically made on histologic examination with immunostaining in suspected cases. Histologically, plasmacytomas are characterized by a diffuse or sheetlike proliferation of plasma cells with varying degrees of maturity and atypia. The nuclei are oval to round and eccentrically located with a dispersed ("clock-face") nuclear chromatin pattern and a clear or halo area $^{3}$ consistent with the microscopic description of the specimen examined from the patient. 
Plasmacytomas may be confused histologically with other benign and malignant conditions such as benign reactive plasmacytosis, undifferentiated carcinoma, non-Hodgkin's lymphoma, malignant melanoma or esthesioneuroblastoma.Therefore, immunohistochemical staining assists in typing the neoplastic and monoclonal nature of the cells ${ }^{3}$. Cytokeratin, an intermediate filament protein of epithelial cells is present in squamous cell carcinoma. LCA is seen in lymphoma and HMB 45 a melanoma associated antigen were all negative in our case except for CD 138.

CD 138 or syndecan-1 is a glycoprotein found in simple epithelial, stratified epithelia, mesenchymal cells and lymphocytes. It is a good marker for multiple myeloma and Reed-Sternberg cell identification. The monoclonal antibody CD138/B-B4 can be used on formalin-fixed, decalcified biopsies to localise normal and neoplastic plasma cells on routine bone marrow sections. ${ }^{12}$

The reported conversion rate of extramedullary plasmacytoma to multiple myeloma is $15-20 \%$ and is associated with poor prognosis. ${ }^{13}$ In a patient with symptoms of myeloma, standards for diagnosis currently require confirmation of one major and one minor criterion or three minor criteria ${ }^{14}$ (Table 2), ruling it out in our case.

Based on the documented radiation sensitivity of plasma cell tumors, the accepted treatment is radiotherapy although surgery provides the same results when a lesion can be completely resected. Like all carcinomas involving the maxillary sinus, the basic surgical starting point is maxillectomy. ${ }^{11}$ As in our patient, the latter may also be combined with radiotherapy depending on resectability of the lesion and may provide the best results ${ }^{7-9,15}$ Complete resection including lymph node dissection of palpable nodes should be attempted for extramedullary plasmacytoma. ${ }^{3}$ Chemotherapy may be considered for patients with refractory disease or relapse. ${ }^{17}$

The clinical course of extramedullary plasmacytoma is more favorable and has better prognosis than multiple myeloma and solitary plasmacytoma of bone, excluding the multiple organ metastases that occur during the end stage of plasma cell malignancy. Long-term follow-up is necessary in order to monitor disease recurrence after surgical excision and post surgical radiotherapy. ${ }^{2}$
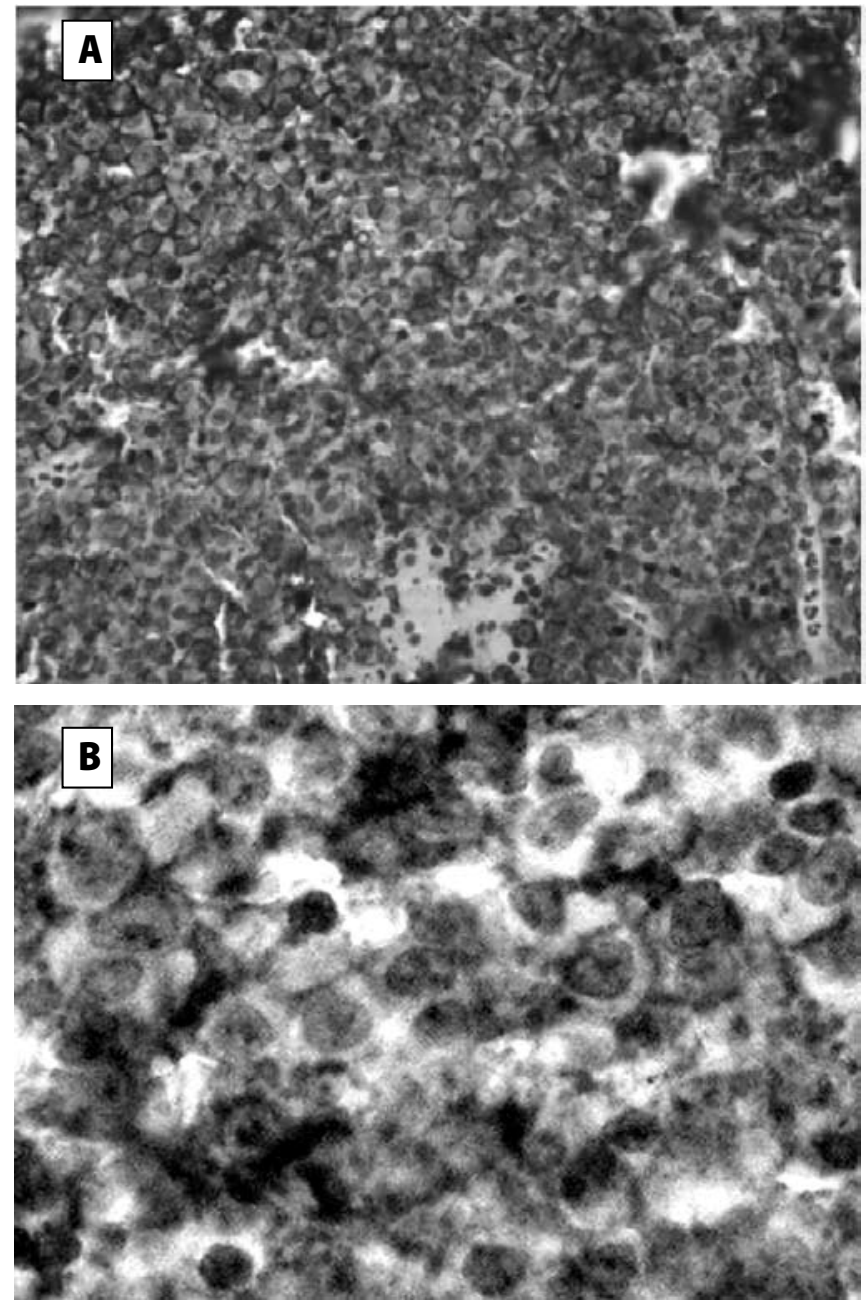

Figure 4. A. Low power B. High power views. CD 138 immunohistochemical stain: Note sheets of plasma cells with varying degrees of maturity and atypia 
CASE REPORTS

\section{Table 1. Initial signs and symptoms of Extramedullary Plasmacytoma}

\begin{tabular}{|c|c|}
\hline Authors & Signs and Symptoms \\
\hline $\begin{array}{l}\text { Ersoy,Sanlier, Yigit, Halefoglu, } \\
\text { Ucak and Altuntas. }{ }^{2}\end{array}$ & Nasal swelling and nasal obstruction \\
\hline Gross, Elishar, Maly , Sichel ${ }^{3}$ & $\begin{array}{l}\text { Soft tissue mass or swelling, or airway obstruction, nasal mass, } \\
\text { nasal discharge, epistaxis, facial pain mimicking recurrent } \\
\text { sinusitis, diffuse infiltration of neighboring structures such as } \\
\text { orbit, hard or soft palate, skin or skull base }\end{array}$ \\
\hline Galieni, Cavo, Pulsoni, et.al.? & $\begin{array}{l}\text { Swelling, headache, nasal discharge, epistaxis, nasal obstruc- } \\
\text { tion, sore throat, hoarseness, dysphonia, dysphagia, epigastric } \\
\text { pain, hemoptysis }\end{array}$ \\
\hline
\end{tabular}

\section{Table 2. Major and minor criteria in diagnosing multiple Myeloma ${ }^{14}$}

\begin{tabular}{l|l}
\multicolumn{1}{c|}{ Major criteria } & \multicolumn{1}{c|}{\begin{tabular}{c}
\multicolumn{1}{c}{ Minor criteria } \\
- A biopsy-proven plasmacytoma.
\end{tabular}} \\
$\begin{array}{l}\text { - A bone marrow sample showing 30\% } \\
\text { plasma cells. }\end{array}$ & $\begin{array}{l}\text { A bone marrow sample showing 10\%-30\% } \\
\text { plasma cells. }\end{array}$ \\
$\begin{array}{l}\text { Elevated monoclonal immunoglobulin levels } \\
\text { in the blood or urine }\end{array}$ & $\begin{array}{l}\text { Minor monoclonal immunoglobulin levels in } \\
\text { blood or urine } \\
\text { Imaging studies revealing holes in bones due to } \\
\text { tumor growth }\end{array}$ \\
& $\begin{array}{l}\text { Antibody levels (not produced by the cancer } \\
\text { cells) in the blood are abnormally low. }\end{array}$ \\
\hline
\end{tabular}

\section{REFERENCES}

1. Soesan M, Paccagnella A, Chiarion-Sileni V, Salvagno L, Fornasiero A, So Zorat $P-L$, et al. Extramedullary plasmacytoma: clinical behaviour and response to treatment. Ann Oncol. 1992;3:51-57.

2. Ersoy O, Sanlier T,Yigit O, Halefoglu AM, Ucak S and Altuntas Y, Extramedullary plasmacytoma of the maxillary sinus. Acta Otolaryngol. 2004; 124: 642-644.

3. Gross M, Elishar R, Maly B, Sichel JY. Maxillary sinus plasmacytoma. IMAJ. 2004; 6:119-120.

4. Kost, KM. Plasmacytomas of the larynx. J Otolaryngol. 1990;19:141-6.

5. Salmito L, Pinto S, Campagnoli EB, Leon JE, Lopes MA, Jorge J. Maxillary lesion presenting as a first sign of multiple myeloma. Med Oral Patol Oral Cir Bucal. 2007;12: E344-7.

6. Kyle RA, Gertz M, Witzig T, Lust J, Lacy M, Dispenzieri A, et. al. Review of 1027 patients with newly diagnosed multiple myeloma.Mayo Clin Proc. 2003; 78:21-33.

7. Galieni P, Cavo M, Pulsoni A, Avivisati G, Bigazzi C, NeriS, et. al. Clinical outcome of extramedullary plasmacytoma. Haematologica. 2000; 85:47-51.

8. Alexiou C, Kau RJ, Dietzfelbinger H, Kremer M, Spiess JC, Schratzenstaller B, et al. Extramedullary plasmacytoma: tumor occurrence and therapeutic concepts. Cancer. 1999; 85:2305-14.

9. Liebross RH, Ha CS, Cox JD, Weber D, Delasalle K, Alexanian R et. al. Clinical course of solitary extramedullary plasmacytoma. Radiother Oncol. 1999 Sep; 52(3):245-9.

10. Bourjat $\mathrm{P}$, Kahn JL, Braun JJ. Imaging of the solitary maxilla-mandibular plasmacytoma. Radiol. 1999; 80:859-62.

11. Thawly S, Panje W, Batsakis J, Lindberg R. Comprehensive Management of Head and Neck Tumors. $2^{\text {nd }}$ ed . Pennsylvania : WB Saunders 1999

12. Wijdene J, Dore JM, Clement C, Vermot-Descroches C. CD138. J Biol Regul Homeost Agents. $2002 ; 16: 152-5$

13. Wanebo H, Geller W, Gerold F. Extramedullary plasmacytoma of the upper respiratory tract recurrence after latency of thirty-six years N Y State J Med 1966; 66:1110-3

14. Bayer-Garnier IB, Prieto VG, Smoller BR. Detection of clonality with kappa and lambda immunohistochemical analysis in cutaneous plasmacytomas. Arch Pathol Lab Med 2004;128:645 8

15. Hu K, Yahalom J. Radiotherapy in the management of plasma cell tumors. Oncology (Huntingt). 2000;14:101-8,111; discussion 111-2.

16. Dimopoulos MA, Kiamouris C, Moulopoulos LA. Solitary plasmacytoma of bone and extramedullary plasmacytoma. Hematol Oncol North Am. 1999; 13:1249-57.

17. Luh S, Lai YS, Tsai CH,and Tsao T.Extramedullary plasmacytoma (EMP): Report of a case manifested as a mediastinal mass and multiple pulmonary nodules and review of literature. World J Surg Oncol. 2007; 5: 123. 